(2) Open Access Full Text Article

\title{
Investigation of Wound Healing and Anti-Inflammatory Activities of Leaf Gel of Aloe trigonantha L.C. Leach in Rats
}

\author{
Haile Tazeze \\ Solomon Mequanente (iD) ${ }^{2}$ \\ Dereje Nigussie (iD ${ }^{3}$ \\ Belete Legesse (iD ${ }^{4}$ \\ Eyasu Makonnen ${ }^{2,4}$ \\ Teklie Mengie (iD ${ }^{5}$ \\ 'Department of Pharmacy, Kidus Petros \\ TB Specialized Hospital, Addis Ababa, \\ Ethiopia; ${ }^{2}$ Department of Pharmacology \\ \& Clinical Pharmacy, School of Pharmacy, \\ College of Health Science, Addis Ababa \\ University, Addis Ababa, Ethiopia; \\ ${ }^{3}$ Ethiopian Public Health Institute, Addis \\ Ababa, Ethiopia; ${ }^{4}$ Center for Innovative \\ Drug Development \& Therapeutics Trial \\ in Africa (CDT-Africa), College of Health \\ Science, Addis Ababa University, Addis \\ Ababa, Ethiopia; ${ }^{5}$ Department of \\ Pharmacy, College of Health Science, \\ Debre Tabor University, Debre Tabor, \\ Ethiopia
}

Background: Traditionally Aloe trigonantha leaf is used for the treatment of different diseases. However, there were no in vivo studies which prove its claimed use for wound healing and anti-inflammatory activity. Therefore, the present study aimed at evaluating the in vivo wound healing and anti-inflammatory effects of the leaf gel of the plant in rats.

Methods: The leaf gel powder of the Aloe trigonantha was prepared after the gel gets lyophilized. It was evaluated for wound healing activity topically by incorporating it in a simple ointment base at a concentration of $5 \%(\mathrm{w} / \mathrm{w})$ and $10 \%(\mathrm{w} / \mathrm{w})$. Excision and incision models were used for wound healing activity in rats. For the excision wound model, wound contraction and period of epithelialization were evaluated, while wound tensile strength was evaluated using an incision wound model. A Xylene-induced ear edema model and cotton pellet-induced granuloma model were used for anti-inflammatory study. The leaf gel powder of Aloe trigonantha was given orally at a dose of 100,200 , and $400 \mathrm{mg} / \mathrm{kg}$ in both models of anti-inflammatory studies. An anti-inflammatory effect was measured by reduction of ear edema weight and reduction of wet exudate and dry granuloma weight in both of xyleneinduced ear edema and cotton pellet-induced granuloma models, respectively.

Results: Treatment of wounds with ointment containing 5\% and $10 \%(\mathrm{w} / \mathrm{w})$ of the gel exhibited a significantly increased wound contraction rate, shorter epithelialization time, and higher skin breaking strength $(p<0.05)$ compared to controls. Aloe trigonantha leaf gel powder also produced dose-dependent significant reductions $(p<0.05)$ of inflammation compared to control in both models.

Conclusion: Data obtained from this study collectively indicated that Aloe trigonantha is a potential wound-healing and anti-inflammatory agent in rat models of wound and inflammation which provides evidence for the traditional claim.

Keywords: Aloe trigonantha, wound healing, anti-inflammatory, granuloma model, ear edema model

\section{Introduction}

Healing of wound is a sophisticated, strictly controlled process that plays a great role in maintaining the protective function of skin. ${ }^{1}$ It is a complex process accomplished by coordinated interactions between cells in the dermis and epidermis. ${ }^{2}$ It is also accomplished by an interaction of blood cells, proteins, proteases, growth factors, and extracellular matrix (ECM) components. ${ }^{3}$

Although wound healing is a normal process which takes place on its own, there are prolonged wounds by different reasons grouped into internal/systemic factors (eg,
Correspondence: Teklie Mengie

Tel +251910IIII53।

Email tekliepharm@gmail.com 
dehydration, abnormal nutritional state, concurrent disease, vascular insufficiency, age, etc.) and external/local factors (pressure, temperature, bacterial burden, wound size, foreign bodies, etc.). ${ }^{4,5}$

Currently a wound is treated by debridement, irrigation, antibiotics, tissue grafts, and proteolytic enzymes methods, which have undesirable side effects. ${ }^{6}$ Because of the possibility of chronic wounds to harbor microbes, topical preparation of the following antibiotics (amikacin, bacitracin, chloramphenicol, clindamycin, gentamicin, nitrofurazone ointment $0.2 \%$ and polymyxin B) are chosen based on their ability to inhibit the growth of pathogenic organisms. ${ }^{7}$ Additionally herbal remedies are known to have high potential for the management and treatment of wounds and burns in many countries. ${ }^{5}$ The healing effects of medicinal plants are thought to be due to the presence of secondary metabolites such as alkaloids, flavonoids, saponins, tannins, essential oils, terpenoids and phenolic compounds. ${ }^{8}$ According to the World Health Organization (WHO) traditional medicine has been promoted as a source of less expensive, comprehensive medical care, especially in developing countries. The majority of the traditional medicines are used for the treatment of wounds and skin disorders, in contrary to a minimum number of modern drugs for these health problem. ${ }^{9}$ More than $70 \%$ of some developed countries and up to $95 \%$ of developing countries population use traditional medicine as primary healthcare to address their healthcare needs and concerns. $^{10}$ Aloe trigonantha (A. trigonantha) L.C. Leach, is belongs to an endemic Aloe species of Ethiopia, which was first described in 1971 and found in an area between Bahir Dar and Gondar in Amhara region of Ethiopia. ${ }^{11}$ Among the total 32 number of endemic Aloe species, 26 are endemic to Ethiopia with $81.25 \%$ of endemism, out of which $A$. trigonantha is one species. ${ }^{12,13}$

Like many other Aloe species traditionally employed, the local people of Bahir Dar and Gondar area extensively use the leaves of $A$. trigonantha for treatment of malaria, eye infection, wound, ${ }^{11}$ and inflammatory diseases. ${ }^{14}$ The leaf latex of $A$. trigonantha has a significant effect against a broad range of bacteria, particularly gram-negative pathogens. ${ }^{14}$ Its latex also revealed significant antimalarial and antifungal effects according to thesis research conducted at Addis Ababa University. ${ }^{11}$

Because of different factors on conventional drugs such as bacterial resistance, adverse effects, costs, environmental degradation, and pollution coupled with improper usage of these medicines, the use of medicinal plants as effective and safer alternatives in the management of various diseases such as wounds has been increased. ${ }^{2,6,15}$

Since conventional drugs result in adverse effects; development of safe, effective, and affordable wound healing and anti-inflammatory products from plant materials is still needed. ${ }^{16}$ Even though A. trigonantha is traditionally used for wound healing, there are no in vivo studies which verify its claimed use for wound healing and antiinflammatory action. Therefore, the present study was aimed to evaluate the in vivo wound healing and antiinflammatory effect of the leaf gel of $A$. trigonantha.

\section{Materials and Methods}

\section{Chemicals, Solvents, and Instruments}

Chemicals, solvents, and instruments used in the present study include: ketamine hydrochloride (Neon Laboratories limited, India), xylene (Farmitalia Carlo Erba, Italy), indomethacin $25 \mathrm{mg}$ capsule (Cadila Pharmaceuticals PLC, Ethiopia), nitrofurazone (2 mg) $0.2 \%$ ointment (Galentic pharma (India) Pvt Ltd.), mercuric chloride (Blulux Analytical Reagent Pvt Ltd, India), potassium iodide (Calibre Engineering Chemistry, India), sulfuric acid (Loba chemical, India), chloroform (Indenta Chemical Pvt Ltd. India), ferric chloride (FeCL3) (Sisco Research Laboratories Pvt. Ltd Maharashtra. India), acetic anhydride (Lot A13/45/67/A), distilled water (Ethiopian Pharmaceutical manufacturing), electronic balance (KERN-ANG 220-4, Germany), lyophilizer (OPR-FDU -5012, Korea), deep freezer (AFTRON AFF 545, Denmark), and a tissue drying oven (Laboratory Oven Lab-Tech, India). All reagents were of analytical grade.

\section{Experimental Plant}

Fresh leaf gel of A. trigonantha (Figure 1A and B) was collected from Amhara regional state in the northwest part of Ethiopia, Kutkuatema small village; $568 \mathrm{Km}$ from Addis Ababa on the way to Bahir Dar, where the leaf gel is used traditionally for various conditions. The fresh leaves were transported using a plastic bag. They were then authenticated by Dr. Getachew Addis, a botanist at Ethiopian Public Health Institute (EPHI), and a sample specimen was deposited at the herbarium of EPHI with a voucher number (HGDB/002/18) for future reference.

\section{Experimental Animals}

Healthy Wistar albino rats of both sexes (6-8 weeks of age) weighing 200-250 g obtained from the animal house 


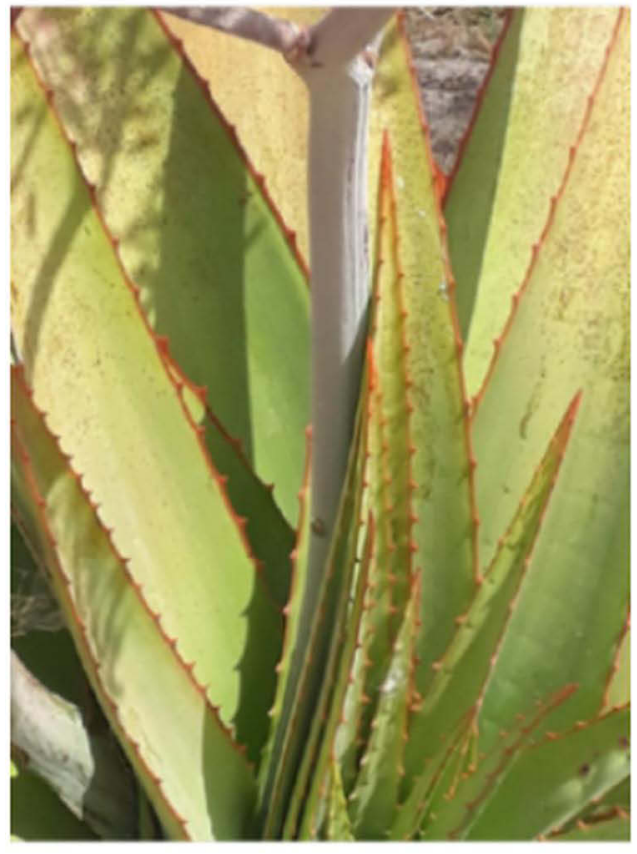

A

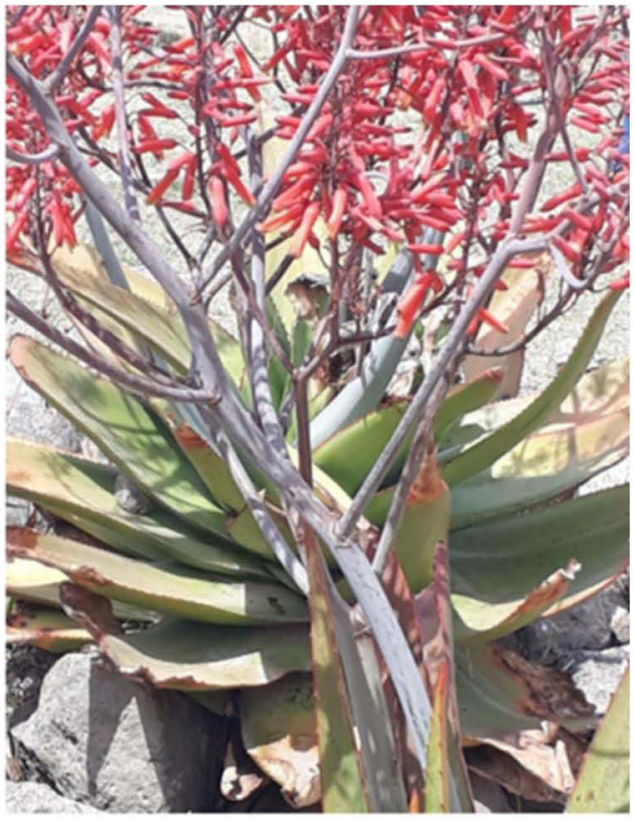

B

Figure I Pictures of Aloe trigonantha L.C. Leach; young leaf $(\mathbf{A})$ and flower of the plant (B).

of the Ethiopian Public Health Institute, Addis Ababa were used for the experiment. The animals were kept in an airconditioned area at room temperature, under a 12 hours dark and 12 hours light cycle. The rats were acclimatized for 1 week before commencement of the study and provided with commercial food pellets and water ad libitum. All procedures and techniques used in this study were conducted in accordance with the national research council guidelines for the care and use of laboratory animals. ${ }^{17}$

\section{Preparation of Plant Material}

Preparation of $A$. trigonantha leaf gel was carried out as per the method defined previously by Rahman et al ${ }^{18}$ and Farzadinia et al. ${ }^{19}$ Briefly the whole leaf was washed with distilled water. Then spikes and margins were avoided before slicing the leaf, and the cortex was carefully separated from the parenchyma using a knife. Fresh A. trigonantha fillets were cut into smaller pieces and blended with a electrical blender to homogenize with a little amount of water. The homogenate was kept in a deep freezer to minimize enzymatic degradation, air oxidation, and loss of active ingredients. Then it was dried in a lyophilizer under cold vacuum conditions. The dried sample of the plant was pulverised into fine powder using a mortar and pestle. Then the pounded product was kept in a refrigerator in a dark closed bottle container until its use.

\section{Ointment Formulation}

The formula of a simple ointment formulation was used from British Pharmacopoeia (BP, 1988) in order to prepare a simple ointment base for leaf gel ointment formulation. ${ }^{20}$ A total of $300 \mathrm{~g}$ of the simple ointment base was prepared using the reduced formula according to a method described by Gebremeskel et al, ${ }^{21}$ with slight modification on the ratio of ingredients taken (Table 1). Out of this, 100 $\mathrm{g}$ was used as a control and the remaining $200 \mathrm{~g}$ was used to prepare $100 \mathrm{~g}$ of each $5 \%$ and $10 \%$ medicated ointments of $A$. trigonantha powder. First, all the ingredients of the simple ointment base were mixed, heated gently with stirring until homogenous, and stirred until cool. Then, to prepare the $5 \%$ and $10 \%$ ointment preparation, $5 \mathrm{~g}$ and 10 $\mathrm{g}$ of the of $A$. trigonantha powder were measured and added to $95 \mathrm{~g}$ and $90 \mathrm{~g}$ of the base, respectively, mixing with the simple ointment (base) by levigation on the surface of the ointment slab to make ointment of uniform consistency and smooth texture. ${ }^{22}$

\section{Acute Oral and Dermal Toxicity Tests}

The limit test was done as per organization for economic cooperation and development (OECD) guidelines-425 in 
Table I Master Formula and Reduced Formula for Simple Ointment Formulation

\begin{tabular}{|l|l|l|}
\hline Ingredients & Master Formula (gm) & Reduced Formula (gm) \\
\hline Wool fat & 50 & 15 \\
Hard paraffin & 50 & 15 \\
White soft paraffin & 850 & 255 \\
Cetostearyl alcohol & 50 & 15 \\
QS & 1000 & 300 \\
\hline
\end{tabular}

Abbreviation: QS, quantity sufficient.

five female rats (6-8 weeks) weighting $200-250 \mathrm{~g}$. The rats were nulliparous and non-pregnant, and a dose of $2,000 \mathrm{mg} / \mathrm{kg}$ of the test substance in distilled water was first given for one female rat. This rat was followed for 24 hours, with special attention given during the first 4 hours to observe survival and any sign of acute behavioral and anatomical change. After confirming the survival of this rat, the remaining four rats were administered the same concentration of the gel powder sequentially to test the toxicity of the plant on all rats. Food was given 4 hours after administration of the test substance. The rats were then observed every day for 14 days for any signs of toxicity and/or mortality as well as to follow if any gross behavioral and autonomic profiles changed. ${ }^{23}$

Acute dermal toxicity was determined according to OECD $404,{ }^{24}$ in three female nulliparous and nonpregnant rats. Approximately 24 hours before the test, fur was removed by closely clipping the dorsal area of the trunk on both flanks using a suitable depilatory material. Special attention was given not to abrade the skin. Skin was washed with sterile water a day before the toxicity test procedure. A limit test dose of $2,000 \mathrm{mg} / \mathrm{Kg}$ of the $10 \%(\mathrm{w} / \mathrm{w})$ leaf gel ointment was applied on the shaved back of the rats within a range that was approximately $10 \%$ of the body surface area and held in contact to the skin with a gauze patch to facilitate good contact and uniform distribution of the test chemical on the skin for the duration of the exposure period ( 24 hours). ${ }^{25}$ The test was first conducted in a single rat for initial testing, and then after observing the response of the first rat for 24 hours a confirmatory test was done on another two rats simultaneously. At the end of the exposure period, the ointment was removed and the animals were observed for 14 days for development of any adverse skin reactions like inflammation, irritation, or redness. Behavior, general condition, posture and reflexes, attitude towards food, and water were also evaluated.

\section{Grouping and Dosing of Experimental Animals}

For the excision wound model the animals were randomly divided into eight groups of six rats per group as follows. The first group was treated with simple ointment (negative control). The second group was treated with nitrofurazone $0.2 \%$ ointment (positive control). The third and fourth groups were treated with 5 and $10 \%(\mathrm{w} / \mathrm{w})$ crude gel ointments of $A$. trigonantha. The same procedures were also used for the incision wound model except in the fifth group, ie, the untreated group.

For anti-inflammatory activity evaluation in two models, the rats were randomly assigned into five groups of six rats per group, in both xylene-induced ear edema and the cotton pellets-induced model. The first two groups served as negative (Distilled water at a dose of $10 \mathrm{~mL} / \mathrm{kg}$ ) and positive (indomethacin $10 \mathrm{mg} / \mathrm{kg}$ ) controls for both models. The remaining three different doses of the dried leaf gel powder $(100 \mathrm{mg} / \mathrm{kg}, 200 \mathrm{mg} / \mathrm{kg}$, and $400 \mathrm{mg} / \mathrm{kg})$ were assigned to groups three, four, and five, respectively. The doses $(100,200$, and $400 \mathrm{mg} / \mathrm{kg}$ ) were selected based on results of the oral limit test. The whole administrations were given orally. Both the dried gel powder and the standard drug were dissolved in distilled water to get an oral suspension and administered orally.

\section{Wound Healing Models Excision Wound Model}

The excision wound was done according to techniques described by Subalakshmi et al. ${ }^{26}$ On the day of inducing wounds, animals were anesthetized by intraperitoneal injection of ketamine in $1 \mathrm{~mL} / \mathrm{kg}$ and the backs of the animals were shaved with scissors. Then, a circular area was marked on the shaved area and the full thickness of the marked area was carefully excised using a razor blade and $\mathrm{n}$ about $450 \mathrm{~mm}^{2}$ wound area was formed. The wound was hemostasis with cotton swab soaked in normal saline. Twenty-four hours afterwound creation, both controls and 
plant product which was prepared in the form of ointments were applied gently once a day to cover the wounded area for 21 days. Then, wound contraction was monitored and measured as a percent of contraction every 3 day.

$$
\% \text { Wound contraction }=\frac{\begin{array}{l}
\text { Initial wound size } \\
- \text { specificday wound size }
\end{array}}{\text { Initial wound size }} X 100
$$

The period of epithelialization was also calculated as the number of days required for falling off the dead tissue remnants without any residual raw wound. ${ }^{6}$

\section{Incision Wound Model}

The measure of tensile strength was performed according to techniques used Mulisa et al. ${ }^{27}$ Rats were anesthetized in the same manner described for an excision wound model before wounding them. Then, a $3 \mathrm{~cm}$ long longitudinal paravertebral incision was made through the skin and subcutaneous tissue using a razor blade, after the dorsal fur of each rat had been shaved with scissors. The parted skin was sutured $1 \mathrm{~cm}$ apart using catgut and a curved needle. The continuous thread (polyglycolic acid 2/0) catgut on both wound edges was tightened for good closure of the wounds. After 24 hours of wound creation (on 1st day), rats were treated topically with the test substance and reference drugs for the consecutive 9 days. The sutures were removed on the 8 th day and tensile strength was measured on the 10th day using a continuous water flow method.

The anesthetized rats were then laid on the table and forceps were applied on the back of the rats $1 \mathrm{~cm}$ away from the sutured skin (Figure 2). The forceps on one side of the rat was tied firmly to a stable metal stand fixed to the operation table, whereas the other side forceps was connected to an empty polythene bag by string running over a pulley and the bag was connected to a water reservoir. Wound tensile strength was measured by constant and continuous water flow technique which was released from the reservoir into the plastic bag. The gradual increased weight acted as a pulling force to disrupt the wound. Then the rubber tube was clamped as soon as the stitched wound began to open and the polythene container was weighed. So, the weight of the liquid was recorded as the weight required to break the suture and used to measure the tensile strength. The tensile strength was then calculated as follows:

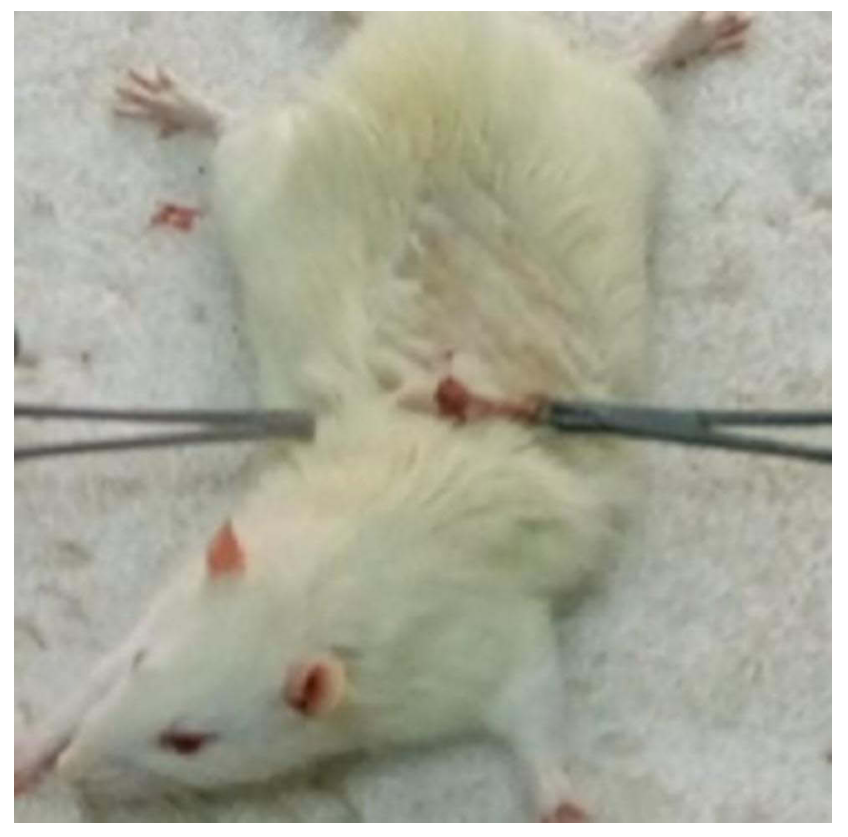

Figure 2 Water flow technique to measure tensile strength of skin wound.

Percent tensile strength of leaf gel

$=\frac{\text { Tensile Strenth }(\text { leaf gel })-\text { Tensile Strength }(\mathrm{SO})}{\text { Tensile Strength }(\mathrm{SO})} X 100$

Percent tensile strength of reference

$=\frac{\text { Tensile Strength }(\text { reference })-\text { Tensile Strength }(\mathrm{SO})}{\text { Tensile Strength }(\mathrm{SO})} X 100$

Percent tensile strength of simpleointment

$$
=\frac{\text { Tensile strengh }(\mathrm{SO})-\text { Tensile Strength }(\mathrm{LU})}{\text { Tensile Strenth }(\mathrm{LU})} X 100
$$

Where $\mathrm{SO}=$ simple ointment and $\mathrm{LU}=$ left untreated. ${ }^{27}$

\section{Determination of Anti-Inflammatory Activity Xylene-Induced Ear Edema Model}

Acute anti-inflammatory activity of $A$. trigonantha leaf gel was evaluated by xylene-induced ear edema in rats. An established method described by Kumer et al ${ }^{16}$ was used with slightmodification; rats of both sexes were randomly divided into five groups, as described in the grouping and dosing section.

Acute ear edema was induced by topical application of $30 \mu \mathrm{L}$ of xylene on the anterior and posterior surfaces of the right ear lobe of each animal, 1 hour after respective treatment. The left ear was untreated with xylene and served as control. The experimental animals were 
sacrificed ( 2 hours after xylene application) and $10 \mathrm{~mm}$ diameter circular sections of both ears were punched out. Finally, the cut portion of each ear was weighed accurately. The weight of ear edema was calculated from the difference between the weight of the right ear and weight of the left ear. Then the percentage inhibition of ear edema was determined by the following formula.

$$
\begin{aligned}
& 1 \text { - weight of edema leaf gel or standard }(\mathrm{mg}) \\
& \text { Inhibition }(\%)=\frac{- \text { Tensile Strength }(\mathrm{LU})}{\text { weight of edema }(\text { negative control })(\mathrm{mg})} X 100
\end{aligned}
$$

\section{Cotton Pellet-Induced Granuloma Model}

The method described by Mengi and Bakshi ${ }^{28}$ was followed to assess the exudate formation and proliferative (granulomatous) components of chronic inflammation. Male Wistar albino rats (200-250 g; 6-8 weeks) were fasted overnight with free access to water. The rats were randomly divided into five groups, six rats per group. Each group was treated in the same manner as that of the xylene-induced ear edema model and treatments were given daily for 7 days orally. A sterile cotton pellet was prepared by rolling of a cotton piece of $20 \pm 1 \mathrm{mg}$ weight and sterilized by autoclaving for 2 hours at $120^{\circ} \mathrm{C}$. Thirty minutes after treatment with the reference drug and test agent, the rats were anesthetized with ketamine at a dose of $1 \mathrm{~mL} / \mathrm{kg}$, and a subcutaneous tunnel was made aseptically using blunted forceps and surgical blade on both sides of the groin. Two sterilized cotton pellets weighing $20 \pm 1 \mathrm{mg}$ each were then implanted bilaterally in the subcutaneous tunnel and sutured with chromic catgut (polyglycolic acid 2/0). On the 8th day, the rats were sacrificed after being anesthetized with ether. The pellets surrounded by granuloma tissue were freed from extraneous tissue after it carefully dissected out. Then, the wet weight was taken immediately after removal before it dried at 60 or $120^{\circ} \mathrm{C}$ for 24 hours and the net dry weight was determined. The exudate amount $(\mathrm{mg})$, granulation tissue formation (mg), and percent inhibition of exudate and granuloma tissue formation were calculated according to the formula given below following the methods used by Aishwarya et al. ${ }^{29}$

The measure of exudate formation $=$ Immediate wet weight of pellet - Constant dry weight of the pellet.

The measure of granuloma tissue formation $=$ Constant dry weight - Initial weight of the cotton pellet.

The exudate amount $(\mathrm{mg})$, granulation tissue formation (mg), the percent inhibition of exudate and granuloma tissue formation were calculated according to the formula described below.

$$
\begin{aligned}
& \text { Exudate inhibition }(\%) \\
& \qquad=\left(1-\frac{\text { exudate in treated group }}{\text { exudate in controls }} X 100\right)
\end{aligned}
$$

$$
\begin{aligned}
& \text { Granulomainhibition }(\%) \\
& \qquad=\left(1-\frac{\text { granuloma in treated group }}{\text { granuloma in control group }} X 100\right)
\end{aligned}
$$

\section{Preliminary Phytochemical Screening of Crude Leaf Gel}

The qualitative screening of secondary metabolites was carried out following standard procedures to identify the presence of alkaloids, flavonoids, glycosides, terpenoids, saponins, tannin, and steroids.

\section{Test for Alkaloids}

Ten milligrams of plant dried gel sample was dissolved with $5 \mathrm{~mL}$ of distilled water, two drops of Mayer's reagent was added in a test tube. The appearance of white creamy precipitate was considered as the indication of the presence of alkaloids. ${ }^{30}$

\section{Test for Flavonoids}

Ten milligrams of the gel was dissolved with $5 \mathrm{~mL}$ of water, a few drops of $2 \%$ lead acetate solution was added. The configuration of yellow color was taken as evidence for the presence of the flavonoids in the plant leaf gel. ${ }^{31}$

\section{Test for Glycoside}

About $20 \mathrm{mg}$ of the gel powder was treated with $2 \mathrm{~mL}$ of glacial acetic acid solution which was contained in one drop of $2 \%$ ferric chloride solution and $1 \mathrm{~mL}$ of concentrated $\mathrm{H}_{2} \mathrm{SO}_{4}$. A reddish brown color formed at the junction of the two layers was taken as an indication of the presence of glycoside in the leaf gel. ${ }^{31}$

\section{Test for Terpenoids}

Fifty milligrams of the gel powder was dissolved in $5 \mathrm{~mL}$ of distilled water and evaporated on the water path after being mixed with $2 \mathrm{~mL}$ of chloroform then boiled with $2 \mathrm{~mL}$ of $\mathrm{H}_{2} \mathrm{SO}_{4}$ concentrated. A grey color indicated the presence of terpenoids. ${ }^{32}$

\section{Test for Saponins}

Five milliliters of distilled water was added to $50 \mathrm{mg}$ of crude plant gel product in a test tube and was shaken vigorously. The foam formation was used as an indication for the presence of saponins. ${ }^{32}$ 


\section{Test for Tannins}

A small amount of the gel was dissolved in $2 \mathrm{~mL}$ of water, and then four drops of diluted ferric chloride solution was added. A green precipitation indicated the presence of tannins compound in the plant. ${ }^{31}$

\section{Test for Phenols and Tannins}

Two milliliters of $2 \%$ solution of $\mathrm{FeCl}_{3}$ was added to crude leaf gel. Black or blue-green color were used as an indication for the presence of tannins and phenols. ${ }^{32}$

\section{Test for Steroids}

Two milliliters of each chloroform and concentrated $\mathrm{H}_{2}$ $\mathrm{SO}_{4}$ were mixed with $50 \mathrm{mg}$ of the crude powder of the leaves gel. THe presence of red color in the lower chloroform layer was used as an indication of steroid availability. ${ }^{32}$

\section{Data Analysis}

All statistical analyses were performed using an international business machine of statistical package for the social Sciences, (IBM SPSS), version 25 for windows (SPSS Inc, Chicago, IL). Statistical differences between groups were analyzed by one-way analysis of variance (ANOVA) followed by Tukey post hoc test for multiple comparisons to compare results among groups. The experimental results were expressed as mean \pm standard error of the mean (SEM) and $p<0.05$ was considered as statistically significant for each parameter. The analyzed data were then presented using tables and figures.

\section{Results}

\section{Acute Oral Toxicity Effect of Aloe trigonantha}

Acute oral toxicity study results showed that the plant leaf gel was safe at least up to the tested dose. Physical and behavioral observations of the experimental animals revealed no visible overt signs of acute toxicity like lethargy, tremor, fatigue, paralysis, autonomic, and behavioral changes. Therefore, the lethal dose of the gel powder was greater than $2,000 \mathrm{mg} / \mathrm{kg}$. None of the rats died, and also there was no observed sign of toxicity till the end of the 14th day.

\section{Acute Dermal Toxicity Effect of Aloe trigonantha}

After application of $10 \%$ ointment of the gel, there was no sign of inflammation, irritation, or redness at the site of application and no changes were observed in the fur, eyes, and behavior of treated animals. There were also no overt signs and symptoms observed when the animals were monitored for 48 hours. Moreover, no signs of toxicity, no edema and erythema, as well as no mortality were noted during the 14 days cage side observation. This indicates that the plant is nonirritant and safe to the animal in dermatological applications at least up to the applied concentration.

\section{Effect of Aloe trigonantha on Wound Healing Excision Wound Model}

The dried leaf gel powder formulated in ointment form was found to be highly active on excision wounds. This was shown by the percent of wound contraction and epithelialization period that shows the rate at which wound healing progresses. The test substance treated animal showed a fast contraction of wound compared to the simple ointment treated rat (Figure 3). The results obtained from the excision wound experiment are summarized in Table 2.

The rats treated with $A$. trigonantha leaf gel ointment were found to have good wound contraction and a fast epithelialization period compared to ointment base treated group rats (Table 2). Rats treated with $10 \%(\mathrm{w} / \mathrm{w})$ gel ointment and $0.2 \%$ nitrofurazone ointments showed a significant decrease $(17.1 \%$ and $18 \%$, respectively, $p<0.05)$ in epithelialization period as evidenced by the shorter period for fall of the dead tissue remnants. Likewise, the $5 \%(\mathrm{w} / \mathrm{w})$ ointment treated group also exhibited a significant decrease $(12.6 \%, p<0.05)$ in epithelialization period compared to the control group with a slightly lower percent of period/prolonged number of days required for epithelialization than $10 \% \mathrm{~A}$. trigonantha gel ointment. Similarly, the wound contraction of the A. trigonantha gel ointment treated groups between each other showed that the $10 \%$ ointment was statistically significant at day 15 and day 18 compared to $5 \%$ of the gel ointment.

The wound area of all groups were measured on the 3rd, 6th, 9th, 12th, 15th, 18th, and 21st days for excision wound model and percentages of wound contraction were calculated on these days. Simple ointment treated rats showed a lower percentage of wound contraction. An increased percentage of wound contraction was observed in animals treated with $10 \%$ ointment (Figure 3) and nitrofurazone starting from the 9th day of wounding $(p<0.05)$. Treatment 


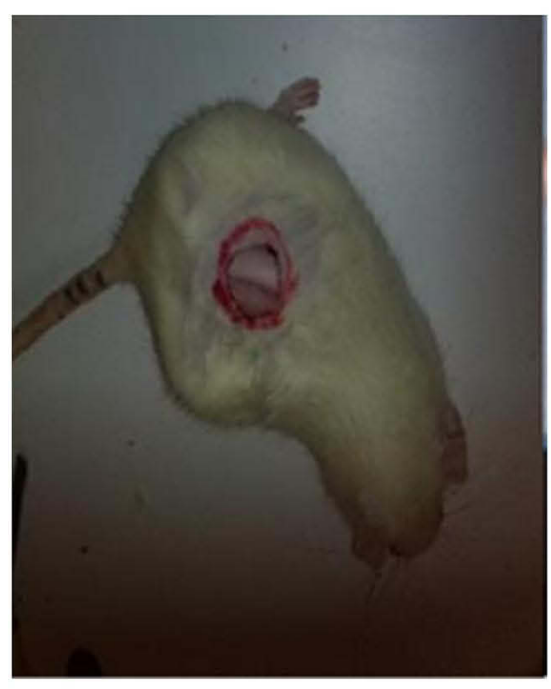

A

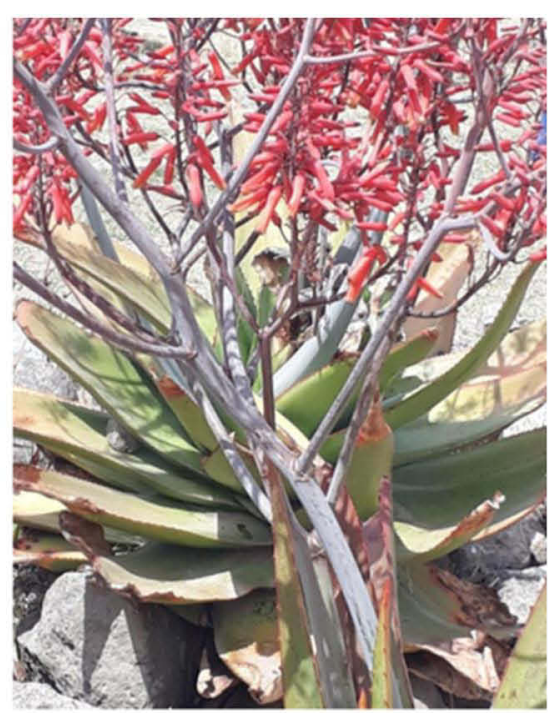

B

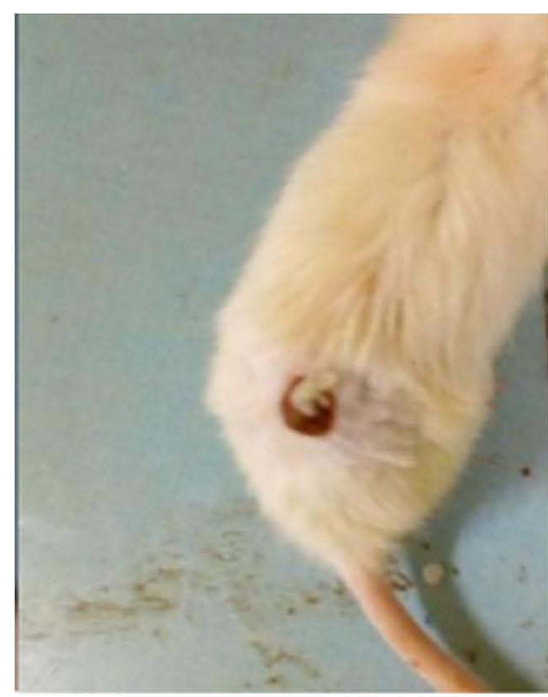

C

Figure 3 Pictures of excision wound at day 0 of wounding $(\mathbf{A})$, day 18 of $10 \%$ A. trigonantha gel treated rat $(\mathbf{B})$ and day 18 of simple ointment treated rat $(\mathbf{C})$.

with $5 \%$ of the gel ointment revealed significantly higher wound contraction than simple ointment control group, starting from the 12th day $(p<0.05)$ (Table 2).

\section{Incision Wound Model}

The tensile strength effect of $A$. trigonantha on sutured wound by incision wound model was done by water flow technique, as presented in Figure 2, and also demonstrated a wound healing (stitch stability) effect of the gel ointment. The mean tensile strength in the group treated with simple ointment tended to increase by about $4.4 \%$ compared to untreated controls, which failed to reach statistical significance. However, tensile strength was significantly increased by about $26.5 \%, 37.6 \%$, and $38.3 \%(p<0.05)$ with $5 \%$ gel ointment, $10 \%$ gel ointment, and nitrofurazone $0.2 \%$ ointment, respectively, compared to controls treated with simple ointment. The $10 \%$ A. trigonantha gel ointment and nitrofurazone also gave a significant tensile strength effect compared to the
$5 \%$ gel ointment $(p<0.05)$ (Table 3). Generally, the 10\% leaf gel ointment gave a significant wound breaking strength than the $5 \%$ gel ointment and simple ointment treated group and comparable to the nitrofurazone $0.2 \%$ ointment treated group.

\section{Anti-Inflammatory Activity of Aloe trigonantha Gel Xylene-Induced Ear Edema Model}

In an acute inflammation study of xylene-induced ear edema model, the plant material showed concentration based inhibition of inflammation. The highest dose (41.5\%) showed comparable inhibition of inflammation with indomethacin $(42.6 \%)$ and revealed a significant effect compared to the negative control group $(p<0.05)$. The $200 \mathrm{mg} / \mathrm{kg}$ dose also significantly inhibited inflammation by inhibiting ear edema $(p<0.05)$ compared to the negative control group (Table 4).

Table 2 Effect of Aloe trigonantha Leaf Gel Ointment on Percent of Wound Contraction and Period of Epithelialization by Excision Wound Model in Rats

\begin{tabular}{|c|c|c|c|c|c|c|c|c|}
\hline \multirow[t]{2}{*}{ Groups } & \multicolumn{7}{|c|}{ Percent of Contraction } & \multirow{2}{*}{$\begin{array}{l}\text { Period of } \\
\text { Epithelialization } \\
\text { (in Days) }\end{array}$} \\
\hline & Day 3 & Day 6 & Day 9 & Day 12 & Day 15 & Day 18 & Day 21 & \\
\hline I & $14.25 \pm 1.64$ & $31.30 \pm 2.13$ & $50.25 \pm 3.57$ & $66.93 \pm 3.67$ & $81.88 \pm 1.08$ & $88.72 \pm 1.02$ & $95.16 \pm 0.91$ & $18.50 \pm 0.43$ \\
\hline II & $|8.7| \pm 1.15$ & $41.68 \pm 3.29$ & $70.4 \pm 1.32 a^{*}$ & $87.79 \pm 0.94 a^{*}$ & $93.67 \pm 0.54 \mathrm{a}^{* *}$ & $97.81 \pm 0.27 a b^{*}$ & $99.21 \pm 0.18 \mathrm{a}^{*}$ & $15.17 \pm 0.31 \mathrm{a}^{*}$ \\
\hline III & $\mid 6.72 \pm 2.81$ & $34.58 \pm 3.34$ & $57.75 \pm 3.27$ & $79.77 \pm 2.53 \mathrm{a}^{*}$ & $88.43 \pm 1.96 a^{*}$ & $94.42 \pm 1.12 a^{*}$ & $97.42 \pm 0.43 \mathrm{a}^{*}$ & $16.17 \pm 0.48 a^{*}$ \\
\hline IV & $18.08 \pm 1.25$ & $41.22 \pm 2.74$ & $70.42 \pm 1.2 a^{*}$ & $86.69 \pm 1.63 \mathrm{a}^{*}$ & $93.6 I \pm 0.77 a^{*} b^{*}$ & $97.77 \pm 0.45 a * b *$ & $99.06 \pm 0.21 \mathrm{a}^{*}$ & $15.33 \pm 0.49 \mathrm{a}^{*}$ \\
\hline
\end{tabular}

Notes: All values are expressed as Mean \pm SEM $(n=6)$; Analysis was performed by one-way ANOVA; a: compared against simple ointment; b: compared against $5 \%$ gel; statistical significance is denoted by $*_{p}<0.05$; I: simple ointment; II: nitrofurazone ointment; III: $5 \%$ leaf gel ointment; IV: $10 \%$ leaf gel ointment. 
Table 3 Effect of Aloe trigonantha on Tensile Strength in Incision Model Using Continuous Water Flow Technique Rats

\begin{tabular}{|l|l|l|}
\hline Group & $\begin{array}{l}\text { Tensile Strength in Gram (Mean } \pm \\
\text { SEM) }\end{array}$ & \% Tensile Strength \\
\hline I & $342.33 \pm 5.302$ & - \\
II & $357.33 \pm 6.38$ I & $4.4 \%$ \\
III & $494.00 \pm 6.787 \mathrm{a} * \mathrm{~b} * \mathrm{c} *$ & $38.3 \%$ \\
IV & $452.17 \pm 6.483 \mathrm{a} * \mathrm{~b} *$ & $26.5 \%$ \\
V & $491.67 \pm 7.032 \mathrm{a} * \mathrm{~b} * \mathrm{c} *$ & $37.6 \%$ \\
\hline
\end{tabular}

Notes: All values are expressed as Mean $\pm \operatorname{SEM}(n=6)$; Analysis was performed by one-way ANOVA; a: compared against untreated group, b: compared against simple ointment; c: compared against $5 \%$ gel ointment; statistical significance is denoted by ${ }^{*} p<0.05$; I: left untreated; II: simple ointment; III: nitrofurazone ointment; IV: $5 \%$ leaf gel ointment; $\mathrm{V}$ : $10 \%$ leaf gel ointment.

Table 4 Acute Inflammation Inhibition Effects of Aloe trigonantha Using Xylene-Induced Ear Edema Model in Rats

\begin{tabular}{|l|l|l|}
\hline Substance Given & Edema Weight (mg) (Mean \pm SEM) & $\%$ Inhibition of Edema \\
\hline I & $10.83 \pm 0.49$ & \\
II & $6.22 \pm 0.64 * a$ & $42.61 \%$ \\
III & $7.92 \pm 1.22$ & $26.6 \%$ \\
IV & $7.25 \pm 1.01 *_{a}$ & $33.07 \%$ \\
V & $6.33 \pm 0.70 * a$ & $41.54 \%$ \\
\hline
\end{tabular}

Notes: All values are expressed as Mean \pm SEM $(n=6)$; Analysis was performed by one way ANOVA; a: compared against distilled water treated group; statistical significance is denoted by ${ }^{*} p<0.05$; I: distilled water (control); II: indomethacin $10 \mathrm{mg} / \mathrm{kg}$ (standard); III: $100 \mathrm{mg} / \mathrm{kg}$ leaf gel powder; IV: $200 \mathrm{mg} / \mathrm{lg}$ leaf gel powder; V: $400 \mathrm{mg} / \mathrm{kg}$ leaf gel powder.

\section{Cotton Pellet-Induced Granuloma Model}

The cotton pellet was removed on the eighth day, as shown in Figure 4A, and measured its wet weight then, it was dried in a tissue drying oven for 24 hours (Figure 4B). The A. trigonantha leaf gel powder was found to reduce the weight of cotton pellet exudate and granuloma in a dose-dependent manner (Table 5). It significantly $(p<0.05)$ prevented the formation of inflammatory exudates and granuloma mass at all tested doses compared to the control. Intergroup comparisons revealed that the $400 \mathrm{mg} / \mathrm{kg}$ is significantly superior to the 200 and $100 \mathrm{mg} / \mathrm{kg}$ in both exudate and granuloma inhibition,

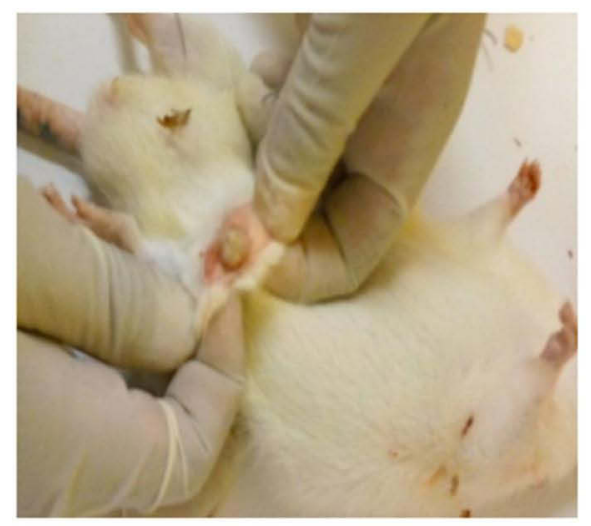

A similarly the $200 \mathrm{mg} / \mathrm{kg}$ was also significantly higher than $100 \mathrm{mg} / \mathrm{kg} \quad(p<0.05)$. It was also shown that $400 \mathrm{mg} / \mathrm{kg}$ gave a relatively comparable effect to indomethacin in both exudate and granuloma inhibition $(p<0.05)$. Furthermore, the anti-inflammatory effect of the A. trigonantha was in dose dependent fashion with $\mathrm{R}^{2}=0.942$. Generally, this plant showed $23.4 \%, 29 \%$, and $34.3 \%$ inhibition of inflammatory exudate and $22.1 \%$, $30.9 \%$, and $38.6 \%$ reduction of granuloma at $100 \mathrm{mg} /$ $\mathrm{kg}, 200 \mathrm{mg} / \mathrm{kg}$, and $400 \mathrm{mg} / \mathrm{kg}$ doses, respectively, while indomethacin showed $34.8 \%$ and $38.8 \%$ inhibition of exudates and granuloma, respectively $(p<0.05)$.

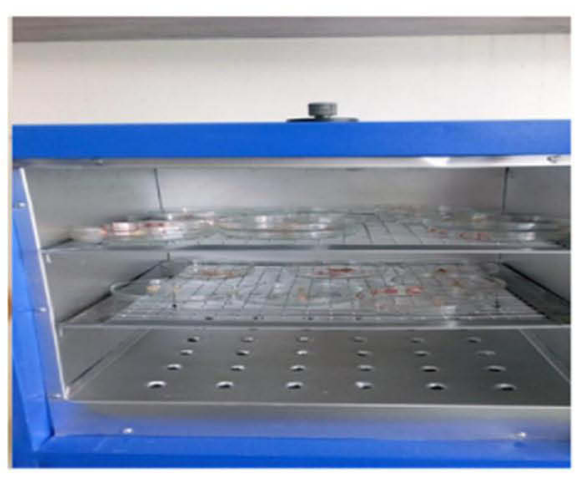

B

Figure 4 Photographs of a freshly removed cotton pellet after seven days of treatment $(\mathbf{A})$ and dried cotton pellet in tissue drying oven after 24 hours (B). 
Table 5 Exudate and Granuloma Inhibition Effects of Aloe trigonantha in Cotton Pellet-Induced Granuloma Model in Rats

\begin{tabular}{|c|c|c|c|c|}
\hline Groups & $\begin{array}{l}\text { Mean Weight of Exudate in } \mathbf{m g} \\
(\text { Mean } \pm \text { SEM) }\end{array}$ & \% Inhibition & $\begin{array}{l}\text { Mean Weight of Granuloma in } \mathbf{m g} \\
(\text { Mean } \pm \text { SEM) }\end{array}$ & \% Inhibition \\
\hline I & $294.500 \pm 1.7654$ & - & $77.670 \pm 1.4298$ & - \\
\hline II & $|93.333 \pm 1.054| * a b c$ & $34.8 \%$ & $47.500 \pm 1.3844 * a b c$ & $38.8 \%$ \\
\hline III & $225.500 \pm 1.5438 *^{*} a$ & $23.4 \%$ & $60.500 \pm 1.118 * a$ & $22.1 \%$ \\
\hline IV & $209.167 \pm 0.6009 * a b$ & $29 \%$ & $53.667 \pm 0.6667 * a b$ & $30.9 \%$ \\
\hline V & $193.500 \pm 0.4282 * a b c$ & $34.3 \%$ & $47.667 \pm 1.022 * a b c$ & $38.6 \%$ \\
\hline
\end{tabular}

Notes: All values are expressed as Mean $\pm \operatorname{SEM}(n=6)$; Analysis was performed by one-way ANOVA; a: compared against distilled water treated group; b: compared to $100 \mathrm{mg} / \mathrm{kg}$; c: compared to $200 \mathrm{mg} / \mathrm{kg}$; statistical significance is denoted by ${ }^{*} p<0.05$; I: distilled water (control); II: indomethacin $10 \mathrm{mg} / \mathrm{kg}$ (standard); III: I00 mg/kg leaf gel powder; IV: $200 \mathrm{mg} / \mathrm{kg}$ leaf gel powder; V: $400 \mathrm{mg} / \mathrm{kg}$ leaf gel powder.

\section{Preliminary Phytochemical Screening of Aloe trigonantha Gel}

Preliminary phytochemical screening of the leaf gel of A. trigonantha indicated the presence of secondary metabolites (Table 6).

\section{Discussion}

In the present study, the wound healing and anti-inflammatory activity of the crude leaf gel of $A$. trigonantha has been evaluated using excision and incision models for the wound healing and xylene-induced ear edema and cotton pellet granuloma method for the anti-inflammatory activity test. Both excision and incision in vivo methods were used in this study because of complexity of wound healing cascade and difficulty of evaluating the effects of an agent in any in vitro model. ${ }^{21}$ The dried gel for topical administration was prepared in the form of ointment to facilitate a sustained drug release at the application sites. This ointment base also has an advantage of acting as a barrier for moisture by hard and white soft paraffin, whereas the wool fat and cetostearyl alcohol are thickeners and because of these characteristics they are used for stabilization of ointment. ${ }^{10}$

Table 6 Preliminary Phytochemical Screening Results of Aloe trigonantha Leaf Gel

\begin{tabular}{|l|l|}
\hline Secondary Metabolites & Availability Results \\
\hline Alkaloids & - \\
Flavonoids & + \\
Glycosides & + \\
Terpenoids & - \\
Saponins & - \\
Tannins & + \\
Steroids & - \\
Phenols and tannins & + \\
\hline
\end{tabular}

Notes: +, presence; -, absence.
The main processes that are involved in wound healing are epithelialization, contraction, and connective tissue deposition and are governed by the biosynthesis and deposition of new collagens at the site of the wound. It also involves migration of endothelial cells, leading to the neovascularization of connective tissues to synthesize the extracellular matrix. $^{33}$ The variable of measurement in the excision wound was the rate of wound contraction and the period of epithelialization. So, visible appearances and measurements of wound contraction become an essential parameters in macroscopic evaluation for wound healing. ${ }^{34}$ This study showed that $A$. trigonantha significantly accelerated the contraction of wounds at $p<0.05$. The $10 \%(\mathrm{w} / \mathrm{w})$ gel ointment treated group revealed significant wound area contraction starting from day 9 of wounding, whereas the $5 \%(\mathrm{w} / \mathrm{w})$ ointment treated group showed statistically significant wound area contraction starting from the 12th day on wards. The outcomes of topical formulation of Aloe gel at $100 \%$ of Aloe being considered most effective, and other with less than $50 \%$ showing less effect, ${ }^{35}$ this evidence supports the result of the present study in which the $10 \%$ is more effective than $5 \%$ gel ointment in both models of wound. This implies that as leaf gel concentration increases the wound contraction rate also increases. The wound contraction could be mediated by specialized myofibroblasts found in the granulation tissue. So, the increase in wound contraction is probably due to the ability of the gel to enhance the activity of fibroblasts. ${ }^{34}$

Re-epithelialization is mandatory for restoration of the integrity of the skin and makes it less vulnerable to infection. The leaf gel ointment treated rats showed a decreased time to epithelialization compared with the control group (Table 2). The period of epithelialization was significantly reduced from 18.5 days (negative control) to 15,16 , and 15 days for nitrofurazone, $5 \%$ and $10 \%$ gel ointment treated groups, respectively. Shortening of the epithelialization 
period could be due to proliferation of the epithelial cells and increasing in their viability by the crude gel ointment of the plant. ${ }^{27}$ The anti-inflammatory effect or a probable induction of macrophage cell proliferation, stimulation of fibroblast migration, and proliferation and production of collagen could be the possible mechanisms of the gel ointment for its wound healing potential. ${ }^{10}$

The incision wound treated with leaf gel ointment showed a significant tensile strength in both the 5\% and $10 \%$ gel ointment treated groups (Table 3). This tensile strength effect could be associated with the increment of collagen synthesis, angiogenesis, fibroblast growth, and stabilization of fibers with crosslinking of the protein. ${ }^{6}$ Therefore, the overall effect improves circulation for oxygen and nutrients supply that are vital for the wound healing cascade. ${ }^{21}$

Inflammation could occur in three distinct phases, such as an acute transient phase characterized by local vasodilation and increased capillary permeability, sub-acute phase, characterized by infiltration of leukocytes and phagocytic cells, and chronic proliferative phase, in which tissue degeneration and fibrosis occurs. The acute vascular process results from vasodilation and capillary permeability, leading to hyperemia and edema formations at the inflammatory site. These processes are all accompanied by proinflammatory cytokine, and activations of complement factors. ${ }^{29}$ In acute inflammation testing, xylene was used for induction of inflammation due to a vasodilatation. It is also known to cause local increases in capillary permeability, inflammatory cell infiltration, and ear acute exudative inflammatory edema. During the process of inflammation, vasodilatation brings about plasma extravasation and inflammatory mediators release, which trigger the acute inflammation response. ${ }^{36}$

Acute inflammation induced in a xylene-induced ear edema model is frequently used to validate the in vivo evaluation of anti-inflammatory topical steroids and nonsteroidal anti-inflammatory agents, mainly those inhibiting phospholipase A2. ${ }^{2,37,38}$ It is also partially associated with substance-P and the release of inflammatory mediators such as histamine, kinin, and fibrinolysin. ${ }^{39}$ Kinin is said to be the main mediator of granuloma, as it both causes vasodilation and increases vascular permeability in the early stages of inflammation. ${ }^{40}$ The significant inhibition of inflammation in xylene-induced ear edema in rats $(p<0.05)$ treated with all doses of leaf gel powder indicated that the gel may have an active ingredient that could either antagonize the effect or reduce release of substance-P or any of the above pro-inflammatory mediators.

In the present study, the gel significantly inhibited the xylene induced increases in ear edema weight in a doserelated manner. This inhibition capacity of the gel can be regarded as the evidence of anti-inflammatory efficacy through reducing vasodilation and improving the edematous condition. There was a significant reduction of the ear edema formation at the dose of $400 \mathrm{mg} / \mathrm{kg}$, which showed an activity comparable to standard drug (Table 4). So, the inhibition of ear edema indicated that $A$. trigonantha leaf gel could have attenuated vasodilatations and plasma extravasation of neurogenic inflammation, which were common in the early stage of acute inflammation. Additionally, it may have a membrane-stabilizing effect that reduces capillary permeability and/or has inhibitory effects on mediators. ${ }^{41}$

Excessive proliferation of macrophages, neutrophils, and fibroblast are basic sources of granuloma formation in inflammation. ${ }^{40} \mathrm{~A}$ cotton pellet-induced granuloma model also assesses the ability of agents to reduce leukocyte infiltration and granuloma formation in the area of inflammation, ${ }^{42}$ and the significant effects of this model $(p<0.05)$ indicate that the gel may have a strong ability of reduction in leukocytes migration during the process of inflammation. The gel effectively and significantly reduced cotton pellet-induced exudate and granuloma, thereby suggesting its activity in both the exudative and proliferative phase of the inflammation. This reduction in transudate and granuloma formation by administration of the gel may be correlated with reduction of the number of fibroblasts and the synthesis of collagen and mucopolysaccharides that are involved in the formation of granuloma tissue. ${ }^{41}$

The process of granuloma formation takes place due to the release of pro-inflammatory mediators, lysosomal enzymes, and reactive oxygen species. ${ }^{43}$ The effect of the gel in this model showed significant effects of minimizing both the wet and dry weight $(p<0.05)$ compared to the distilled water treated group (Table 5). The exudate and granuloma inhibition effect could be due to the increased levels of anti-inflammatory cytokines and decreased production of pro-inflammatory mediators like myeloperoxidase, nitric oxide, and some interleukins, or by either inhibiting the lysosomal enzymes or stabilizing the membrane. ${ }^{44}$ Although we have not measured the levels of different anti-inflammatory cytokines or proinflammatory mediators, they may contribute in wound healing and anti-inflammatory properties of the plant gel. 
The preliminary phytochemical screening of the leaf gel of A. trigonantha showed the presence of flavonoid, glycoside, phenols, and tannins (Table 6). The wound healing and anti-inflammation effects of the gel might be due to the presence of any one or more of the above phytochemical constituents. Studies have shown that secondary metabolites like flavonoids are known to have therapeutic values such as antimicrobial, astringent, antiinflammatory, antioxidant, and wound healing effects. ${ }^{25} \mathrm{It}$ also decreases lipid peroxidation by avoiding or slowing the onset of cell necrosis and improving vascularity. The inhibition of lipid peroxidation is believed to increase the viability of collagen (94). According to Cheng et al, ${ }^{45}$ the secondary constituents such as flavonoids, tannins, glycosides, and other phenolic compounds have good antiinflammatory effects. ${ }^{46}$ Tannins and flavonoids are also known by their anti-inflammatory properties via inhibiting enzymes involved in inflammation, especially enzymes involved in the arachidonic acid metabolic pathway, and synthesis of prostaglandins. Tannins could also affect the inflammatory response via free radical scavenging properties, ${ }^{39}$ and inhibition of inductive nitric oxide species in macrophages. ${ }^{47}$ Flavonoids play a role in inhibition of lipoxygenase and cyclooxygenase, an enzyme which is highly involved in induction of inflammation, ${ }^{46}$ and blockage of molecules like cytokines, and matrix metalloproteinase. It has a significant activity in both proliferative and exudative phases of inflammation as well as in the inhibition of the development of the induced granuloma. ${ }^{47}$

Phenolic compounds work in a similar way as nonsteroidal anti-inflammatory drugs do; in addition to cyclooxygenase some phenolic compounds also inhibit other pro-inflammatory mediators by inhibiting their activity or gene expression. According to reports of AmbrizPerez et al, some dietary flavonoids have shown antiinflammatory effects by modulation of the inflammation mediators such as IL- $6 .^{7}$ Pandey et $\mathrm{al}^{48}$ palso report that flavonoid-rich product gives a significant $(p<0.05)$ antiinflammatory effect by inhibiting the expression of inflammatory mediators like Interferon- $\Upsilon$ and tumor necrotic factor- $\alpha$, so this evidence supports that the effects of A. trigonantha gel on inflammation probably depends on its flavonoid content by inhibiting the above proinflammatory factors. Therefore, the presence of flavonoids, tannins, and phenols may be responsible for the wound healing and anti-inflammatory effects of A. trigonantha leaf gel.
In conclusion, the leaf gel of $A$. trigonantha possesses potential wound healing and anti-inflammatory activities which rationalize the folklore therapeutic claim that the plant has been used for. Topical application of the gel ointment on excision as well as incision models revealed comparable wound healing effects to that of the standard $(0.2 \%$ nitrofurazone) ointment. Oral administration of the dried gel also demonstrated a dose-dependent antiinflammatory effect. The anti-inflammatory activity may be attributed to the wound healing effect of the gel. From the present results, A. trigonantha could be considered a future possible wound healing and anti- inflammatory agent.

\section{Ethics Approval}

Ethical clearance and permission were obtained from Addis Ababa University Research and Ethical Review Committee.

\section{Acknowledgments}

We are very grateful to Addis Ababa University for funding the study. The deeply felt and utmost gratitude also goes to advisors Dr Solomon Mequanente and Prof. Eyasu Makonnen as well as co-advisors; Dereje Nigussie and Dr Belete Legesse, for their indispensable guidance, motivation, suggestions, and continuous encouragement during the experiment and write-up of this thesis. Finally our gratitude goes to $\mathrm{Mr}$ Teklie Mengie who helped and coordinated in each step of the experimental procedure in the laboratory as well as in write up of the thesis and preparing the manuscript. ${ }^{49}$

\section{Author Contributions}

All authors made a significant contribution to the work reported, that is in the conception, study design, execution, acquisition of data, analysis, and interpretation, or in all these areas; took part in drafting, revising, or critically reviewing the article; gave final approval of the version to be published; have agreed on the journal to which the article has been submitted; and agreed to be accountable for all aspects of the work.

\section{Funding}

Addis Ababa University provided and CDT-Africa all the required resources for conducting this research project.

\section{Disclosure}

The authors report no conflicts of interest in this work. 


\section{References}

1. Han G, Ceilley R. Chronic wound healing: a review of current management and treatments. Adv Ther. 2017;34(3):599-610. doi:10.1007/s12325-017-0478-y

2. Oguntibeju OO. Medicinal plants and their effects on diabetic wound healing. Vet World. 2019;12(5):653-663. doi:10.14202/vetworld.2019.653-663

3. Sinno H, Prakash S. Complements and the wound healing cascade: an updated review. Plast Surg Int. 2013;2013:1-7.

4. Europe wound management. Guidelines for the Assessment \& Management of Wounds. Northamptonshire Healthcare; 2015:1-37.

5. Namunana S, Lutoti S, Nyamaizi G, et al. Formulation, development and validation of a wound healing herbal ointment from extracts of Bidens pilosa and Aloe barbadensis. J Pharm Pharmacol Res. 2018;02(02):32-38. doi:10.26502/jppr.0008

6. Liu H, Lin S, Xiao D, Zheng X, Gu Y, Guo S. Evaluation of the wound healing potential of Resina Draconis (Dracaena cochinchinensis) in animal models. Evid Based Complement Altern Med. 2013;1(4):1-10.

7. Beshir K. Evaluation of Wound Healing Activity of $70 \%$ Ethanol Leaf Extract of Becium Grandiflorum Lam. (Lamiaceae) in Mice, MSc Thesis. Addis Ababa University; 2017.

8. Laut M, Ndaong NA, Utami T. Cutaneous wound healing activity of herbal ointment containing the leaf extract of Acalypha indica L. on mice. J Phys. 2019;1146(1):1-6.

9. Nagesh H, Basavanna P, Kishore M. Evaluation of wound healing activity of ethanolic extract of Azadirachta indica leaves on incision and excision wound models in Wister albino rats. Int J Basic Clin Pharmacol. 2015;4 (6):1178-1182. doi:10.18203/2319-2003.ijbcp20151354

10. Demilew W, Adinew GM, Asrade S. Evaluation of the wound healing activity of the crude extract of leaves of Acanthus polystachyus Delile (Acanthaceae). Evid Based Complement Altern Med. 2018;2018 (5):1-9. doi:10.1155/2018/2047896

11. Megersa M. Antimalarial and Antimicrobial Activities of Anthrones and Chromone from the Leaf Latex of Aloe Trigonantha, MSc Thesis. Addis Ababa University; 2013.

12. Demissew S, Nordal I. Aloes and Lilies of Ethiopia and Eritrea. 2nd ed. Addis Ababa, Ethiopia: Shama Books; 2010:1-351.

13. Mekuria A. Chromosome Study on Seven Endemic Aloe Species (Aloaceae) of Ethiopia, MSc Thesis. Addis Ababa University; 2007.

14. Megeressa M, Bisrat D, Mazumder A, Asres K. Structural elucidation of some antimicrobial constituents from the leaf latex of Aloe trigonantha L.C. Leach. BMC Complement Altern Med. 2015;15(1):1-7. doi:10.1186/s12906-015-0803-4

15. Lodhi S, Jain AP, Rai G, Yadav AK. Preliminary investigation for wound healing and anti-inflammatory effects of Bambusa vulgaris leaves in rats. J Ayurveda Integr Med. 2016;7(1):14-22. doi:10.1016/j.jaim.2015.07.001

16. Kumer A, Hashem AK, Biswas K. Antithrombotic and anti-inflammatory activities of leaf methanolic extract of Euphorbia hirta Lin. Int J Complement Altern Med. 2019;12(4):154-162. doi:10.15406/ijcam.2019.12.00466

17. Garber JC, Barbee RW, Bielitzki JT, et al. Guide for the Care and Use of Laboratory Animals. National Institute of Health; 2010:1-218.

18. Rahman S, Islam R, Rana M, et al. Characterization of burn wound healing gel prepared from human amniotic membrane and Aloe vera extract. BMC Complement Altern Med. 2019;5(19):1-15.

19. Farzadinia P, Khatamsaz S, Movahed A, Mohammadi M. Antiinflammatory and wound healing activities of Aloe vera, honey and milk ointment on second-degree burns in rats. Int $J$ Low Extrem Wounds. 2016;1(7):1-7.

20. British Pharmacopoeia. Monographs for Medicinal Substances and Formulated Preparations. London: The Stationery Office; 2009.

21. Gebremeskel L, Bhoumik D, Sibhat GG, Tuem KB. In vivo wound healing and anti- inflammatory activities of leaf latex of Aloe megalacantha baker (Xanthorrhoeaceae). Evid Based Complement Altern Med. 2018;2018(7):1-7. doi:10.1155/2018/5037912
22. Allen LV, Popovich NG, Ansel HC. Ansel's Pharmaceutical Dosage Forms and Drug Delivery Systems. Ninth ed. Lippincott Williams \& Wilkins; 1985.

23. OECD/OCDE. Acute oral toxicity - up-and-down-procedure (UDP). OECD Guidel Test Chem. 2008;425(October):1-27.

24. OECD 404. Guidelines for the testing of chemicals. acute dermal irritation/corrosion. OECD guidel test. Chem Sect Health Effect. 2015;1(July 28th):1-8.

25. Kokane DD, More RY, Kale MB, Nehete MN, Mehendale PC, Gadgoli CH. Evaluation of wound healing activity of root of Mimosa pudica. $\quad J$ Ethnopharmacol. 2009;124(2):311-315. doi:10.1016/j. jep.2009.04.038

26. Subalakshmi M, Saranya A, Uma Maheswari M, Jarina A, Kavimani S. An overview of the current methodologies used for the evaluation of drugs having wound healing activity. Int $J$ Exp Pharmacol. 2014;4(2):127-131.

27. Mulisa E, Asres K, Engidawork E. Evaluation of wound healing and anti- inflammatory activity of the rhizomes of Rumex abyssinicus J. (Polygonaceae) in mice. BMC Complement Altern Med. 2015;15:1-10. doi:10.1186/s12906-015-0878-y

28. Mengi SA, Bakshi VJ. Evaluation of the aqueous extract of Rotula aquatica roots in acute and chronic inflammatory conditions in rats. Pharm Biol. 2009;47(6):491-495. doi:10.1080/13880200902835705

29. Aishwarya MNL, Mounika P, Mounika J, Shankar M, Mallikarjuna G, Niranjan Babu NN. Anti-inflammatory activity of Murraya exotica Linn against cotton pellet induced granuloma in Wistar rats. Int J Pharm Sci Rev Res. 2018;49(22):111-116.

30. Banu KS, Cathrine L. General techniques involved in phytochemical analysis. Int $J$ Adv Res Chem Sci. 2015;2(4):25-32.

31. Kamal T, Muzammil A, Akintunde R, Rahma MS, Omar MN. Preliminary phytochemical screening test of Garcinia griffithii plant. Innova Ciencia. 2012;4(4):68-74.

32. Jaradat N, Hussen F, Ali A. Preliminary phytochemical screening, quantitative estimation of total flavonoids, total phenols and antioxidant activity of Ephedra alata decne. J Mater Environ Sci. 2015;6 (6):1771-1778.

33. Elzayat EM, Auda SH, Alanazi FK, Al-Agamy MH. Evaluation of wound healing activity of henna, pomegranate and myrrh herbal ointment blend. Saudi Pharm J. 2018;26(5):733-738. doi:10.1016/j. jsps.2018.02.016

34. Isabela KR, Agra LLS, Pires PSMC, Eurípedes A, Silva-Filho SS, Barreto E. Evaluation of wound healing and antimicrobial properties of aqueous extract from Bowdichia virgilioides stem barks in mice. Ann Braz Acad Sci. 2013;85(3):945-954. doi:10.1590/S0001-37652013005000049

35. Quave CL. Wound healing with botanicals: a review and future perspectives. Curr Dermatol Rep. 2018;7(4):287-295. doi:10.1007/ s13671-018-0247-4

36. Li C, Wu X, Zhao X, et al. Anti-inflammatory property of the ethanol extract of the root and rhizome of Pogostemon cablin (Blanco) Benth. Sci World J. 2013;1(10):1-12.

37. Tank Chintankumar J, Borkhataria Chetan H, Baria Ashok H, et al. Formulation and evaluation of aceclofenac loaded maltodextrin based proniosome. Int J ChemTech Res. 2009;1(3):567-573.

38. Bagad AS, Joseph JA, Bhaskaran NAA. Comparative evaluation of anti-inflammatory activity of curcuminoids, turmerones, and aqueous extract of Curcuma longa. Adv Pharmacol Sci. 2013;1(11):1-7.

39. Pawar RS, Toppo FA. Plants that heal wounds. A review. Kerba Polonica. 2012;58(1):47-65.

40. Afsar SK, Rajesh Kumar K, Venu Gopal J, Raveesha P. Assessment of anti-inflammatory activity of Artemisia vulgaris leaves by cotton pellet granuloma method in Wistar albino rats. $J$ Pharm Res. 2013;7 (6):463-467. doi:10.1016/j.jopr.2013.04.056

41. Hosseinzadeh H, Haddadkhodaparast MH, Arash AR. Antinociceptive, antiinflammatory and acute toxicity effects of Salvia leriifolia Benth. seed extract in mice and rats. Phytother Res. 2003;17:422-425. doi:10.1002/ptr.1154 
42. Owoyele BV, Nafiu AB, Oyewole IA, Oyewole LA, Soladoye AO. Studies on the analgesic, anti-inflammatory and antipyretic effects of Parquetina nigrescens leaf extract. J Ethnopharmacol. 2009;122 (1):86-90. doi:10.1016/j.jep.2008.11.027

43. Patil KR, Patil CR. Anti-inflammatory activity of bartogenic acid containing fraction of fruits of Barringtonia racemosa Roxb. in acute and chronic animal models of inflammation. $J$ Trad Complement Med. 2017;7(1):86-93. doi:10.1016/j.jtcme.2016.02.001

44. Paschapur MS, Patil MB, Kumar R, Patil SR. Influence of ethanolic extract of Borassus flabellifer L. male flowers (inflorescences) on chemically induced acute-inflammation and poly arthritis in rats. Int $J$ PharmTech Res. 2009;1(3):551-556.

45. Cheng J, Ma T, Liu W, et al. In vivo evaluation of the anti- inflammatory and analgesic activities of compound Muniziqi granule in experimental animal models. BMC Complement Altern Med. 2016;16(1):1-10.
46. Lotanna AD, Emeka IE, Jegbefume OM, Onyeka OC, Adaobi OM, Obiora IS. Mechanisms of anti-inflammatory activity of the leaf extract and fractions of Millettia aboensis. Int Res J Pharm. 2013;4 (9):54-59. doi:10.7897/2230-8407.04912

47. Alemu A, Tamiru W, Nedi T, Shibeshi W. Analgesic and anti-inflammatory effects of $80 \%$ methanol extract of Leonotis ocymifolia (Burm.f.) iwarsson leaves in rodent models. Evid Based Complement Altern Med. 2018;2018(11):1-8. doi:10.1155/2018/ 1614793

48. Pandey S, Cabot PJ, Shaw PN, Amitha K. Anti-inflammatory and immunomodulatory properties of Carica papaya. J Immunotoxicol. 2016;13(4):590-602. doi:10.3109/1547691X.2016.1149528

49. AAU institutional repository. Wound Healing and Anti-Inflammatory Activities of Leaf Gel of Aloe Trigonantha L.C. Leach in Rats, Tazeze, Haile, Thesis. Addis Ababa University; 2020.
Journal of Inflammation Research

\section{Publish your work in this journal}

The Journal of Inflammation Research is an international, peerreviewed open-access journal that welcomes laboratory and clinical findings on the molecular basis, cell biology and pharmacology of inflammation including original research, reviews, symposium reports, hypothesis formation and commentaries on: acute/chronic inflammation; mediators of inflammation; cellular processes; molecular
Dovepress

mechanisms; pharmacology and novel anti-inflammatory drugs; clinical conditions involving inflammation. The manuscript management system is completely online and includes a very quick and fair peerreview system. Visit http://www.dovepress.com/testimonials.php to read real quotes from published authors. 